\title{
Evaluation of an Odour Emission Factor (OEF) to estimate odour emissions from landfill surfaces
}

Federico Lucernoni, Federica Tapparo, Laura Capelli*, Selena Sironi

Politecnico di Milano - Department of Chemistry, Materials and Chemical Engineering "Giulio Natta" Piazza Leonardo da Vinci 32, 20133 Milano, Italy

*Corresponding author: laura.capelli@polimi.it; Tel. +390223993206

\begin{abstract}
Emission factors are fundamental tools for air quality management. Odour Emission Factors (OEFs) can be developed in analogy with the emission factors defined for other chemical compounds, which relate the quantity of a pollutant released to the atmosphere to a given associated activity. Landfills typically represent a common sources of odour complaint; for this reason, the development of specific OEFs allowing the estimation of odour emissions from this kind of source would be of great interest both for the landfill design and management. This study proposes an up-to-date methodology for the development of an OEF for the estimation of odour emissions from landfills, thereby focusing on the odour emissions related to the emissions of landfill gas (LFG) from the landfill surface. The proposed approach is an "indirect" approach based on the quantification of the LFG emissions from methane concentration measurements carried out on an Italian landfill. The Odour Emission Rate (OER) is then obtained by multiplying the emitted gas flow rate by the LFG odour concentration. The odour concentration of the LFG emitted through the landfill surface was estimated by means of an ad hoc correlation investigated between methane concentration and odour concentration. The OEF for the estimation of odour emissions from landfill surfaces was computed, considering the landfill surface as the activity index, as the product between the mean specific LFG flux emitted through the surface resulting from the experimental campaigns, equal to $0.39 \mathrm{I} / \mathrm{m}^{2} / \mathrm{h}$, and its odour concentration, which was estimated to be equal to $105^{\prime} 000$
\end{abstract}


$\mathrm{Ou}_{\mathrm{E}} / \mathrm{m}^{3}$, thus giving an OEF of $0.0113 \mathrm{ou}_{\mathrm{E}} / \mathrm{m}^{2} / \mathrm{s}$. This value, which is considerably lower than those published in previous works, should be considered as an improved estimation based on the most recent developments of the research in the field of odour sampling on surface sources.

Keywords: landfill gas; odour concentration; hood sampling; area sources; olfactometry; methane concentration

\section{INTRODUCTION}

Although odorous compounds are not necessarily toxic or hazardous for human health, it is known that the odours resulting directly or indirectly from human activities may cause adverse effects on citizens (Aatamila et al., 2011; Sucker et al. 2009), and are therefore actually considered as atmospheric contaminants. For this reason, odours are nowadays subject to control and regulation in many countries (Nicell, 2009).

Although there are different approaches that can be adopted to regulate odour-related problems, the most recent odour regulations that have been published around the world are based on the application of dispersion modelling (Sironi et al., 2013). One of the main reasons for the spreading of odour impact assessment approaches based on odour dispersion modelling is that they allow to overcome the limitation of accounting just for the emission at the source, without considering the consequent citizens' exposure to odours (Capelli et al., 2013a). As a matter of fact, besides source characterization and quantification of the Odour Emission Rate (OER), odour impact assessment should involve the consideration of other factors, such as the orography of the terrain where source and receptors are located, meteorology, land use and density of population (Chemel et al., 2012; Schauberger et al., 2012, Hoff et al., 2006). Odour dispersion modelling allow to account for these factors by simulating how odours disperse into the atmosphere, and therefore to calculate ground odour concentration values in each point of the simulation domain. Odour dispersion models also entail the advantage of being not solely descriptive, but also predictive, meaning that they can be applied for the assessment of the odour impact either of existing or of designed plants. 
In the first case, emission data for the model input are generally retrieved experimentally by means of olfactometric campaigns aimed to a detailed quantification of the odour emissions (in terms of ou $/ \mathrm{s}$ ). In the second case, in order to apply odour dispersion modelling to predict the odour impact of a plant, it is mandatory to be able to predict the entity of the odour emissions required as model inputs.

Based on these considerations, it is clear that emission factors and emission inventories are fundamental tools for air quality management (Capelli et al., 2014a). Emission estimates are important for developing emission control strategies, determining applicability of permitting and control programs, evaluating the feasibility and the effects of appropriate mitigation strategies, and a number of other related applications by different users, including national and local agencies, consultants, and industry.

As far as odour emissions are concerned, Odour Emission Factors (OEFs) can be developed in analogy with the emission factors defined by the United States Environmental Protection Agency (1995) for other pollutants/chemical compounds, which relate the quantity of a pollutant released to the atmosphere to a given associated activity. In the estimation of OEFs for industrial plants, these values can be calculated as the emitted odour emission rate (in $\mathrm{ou}_{\mathrm{E}} / \mathrm{s}$ ), divided by a specific activity index, which may be for example the gross weight production, the site surface or a time unit. Based on such considerations, OEFs would represent a simple and effective means to predict the odour emissions from a given plant typology, using one (or more) parameter (activity index) related to the odour emission itself. Of course, OEF, despite their simplicity, allow a rather "rough" estimation of odour emission rates, but knowing the order of magnitude of the odour impact expected is in most cases sufficient in order to evaluate the appropriateness of the location of a new plant or the design of possible odour control systems. Nonetheless, OEFs may be further "refined" by evaluating their dependence from more parameters than just one activity index, such as atmospheric conditions or seasonality (Schauberger et al., 2013).

In the scientific literature it is possible to find some specific studies, giving indications about odour emission factors for some plant typologies, such as for instance composting plants (Sironi et al., 2006), wastewater treatment plants (Capelli et al., 2009), rendering plants (Sironi et al., 2007), and livestock operations (Nicholas et al., 2002; Schauberger et al., 2014). 
A first study on OEFs was published in 2005 (Sironi et al., 2005) regarding the estimation of OEFs for the assessment and prediction of landfill odour emissions, which represent one of the most common sources of odour-related complaint. For this reason, the development of specific OEFs allowing the estimation of odour emissions from this kind of source would be of great interest both for the landfill design and management. Unfortunately, the data presented in the paper of Sironi et al. (2005) should be considered obsolete, mainly due to the use of a sampling technique that was later proven to significantly overestimate emissions (Capelli et al., 2015).

The present study proposes an up-to-date methodology for the development of an OEF for the estimation of odour emissions from landfills, thereby focusing on the odour emissions related to the emissions of landfill gas (LFG) from the landfill surface. As a matter of fact, due to its large extension compared to the other sections of the plant (e.g., fresh waste tipping, torches), as well as to the offensive odour character of LFG (Dincer et al., 2006), this is recognized to be the main source of malodours from landfills (Saral et al., 2009; Sarkar and Hobbs, 2003).

\section{MATERIALS AND METHODS}

\subsection{The Sampling Hood}

Starting December 2014, the research group of the Olfactometric Laboratory of the Politecnico di Milano (LabOlf) uses a specific sampling device for investigations in the field (Capelli et al., 2014b). The hood is based on a design inspired by the models proposed in literature, namely the UK EA design (UK EA, 2010) and a variant proposed by a German research group (Rachor et al., 2013). More in detail, the German design is an evolution of the UK EA proposal and is a cylindrical chamber with a base area of $0.12 \mathrm{~m}^{2}$ and a height of $50 \mathrm{~cm}$, giving an internal volume of $60 \mathrm{I}$. The novel aspect of this hood is that it is equipped with a $3 \mathrm{~m}$ long tube with a $4 \mathrm{~mm}$ inner diameter that assures no overpressures are generated inside the hood during operation due to LFG emission from the surface, while the inner volume is isolated from the outside environment thanks to the long diffusion path imposed, i.e. long tube. The LabOlf research group adopted 
the idea proposed by Rachor et al. in order to realize the hood that is used for sampling on landfill surface, but the design was further modified as shown in Fig.1. The hood has a squared base, $50 \mathrm{~cm} \times 50 \mathrm{~cm}$ and height $10 \mathrm{~cm}$, giving an internal volume of $25 \mathrm{I}$. The main difference with respect to the design proposed by Rachor et al. is the height of the chamber, since in the hood here considered it is significantly lower than 50 $\mathrm{cm}$. This choice was made since the expected phenomenon for the increase of the methane $\left(\mathrm{CH}_{4}\right)$ concentration inside the hood is mainly diffusive, thus very slow, and higher heights would cause the concentration profile inside the chamber to be very inhomogeneous along the hood height. However, the landfill surface soil is by nature inhomogeneous, thus making it unfeasible to use sampling hoods with too small heights. For these reasons, in the end, $10 \mathrm{~cm}$ was deemed a fair trade-off. The hood is made of steel, therefore it is resistant and it can be partially inserted in the soil - in order to minimize LFG leaks - without sustaining damages. The device is also equipped with lateral flanges to avoid complete plunging in the soil, allowing a defined and repeatable insertion length. The $3 \mathrm{~m}$ long open tube, introduced by Rachor et al., granting isobaric operations, in the proposed design is located on a lateral wall of the hood, while another similar $10 \mathrm{~cm}$ tube is located on the top wall of the chamber, allowing to connect the measurement instrument providing the $\mathrm{CH}_{4}$ concentration. The described hood can be operated both as a Static Hood $(\mathrm{SH})$ and as a Flux Chamber ( $\mathrm{FC})$, i.e. static mode and/or fluxed mode. More in detail, as will be explained and discussed in the following paragraphs, odour sampling was performed using the hood as a FC, whereas for the $\mathrm{CH}_{4}$ concentration measurement the static mode was preferred. 


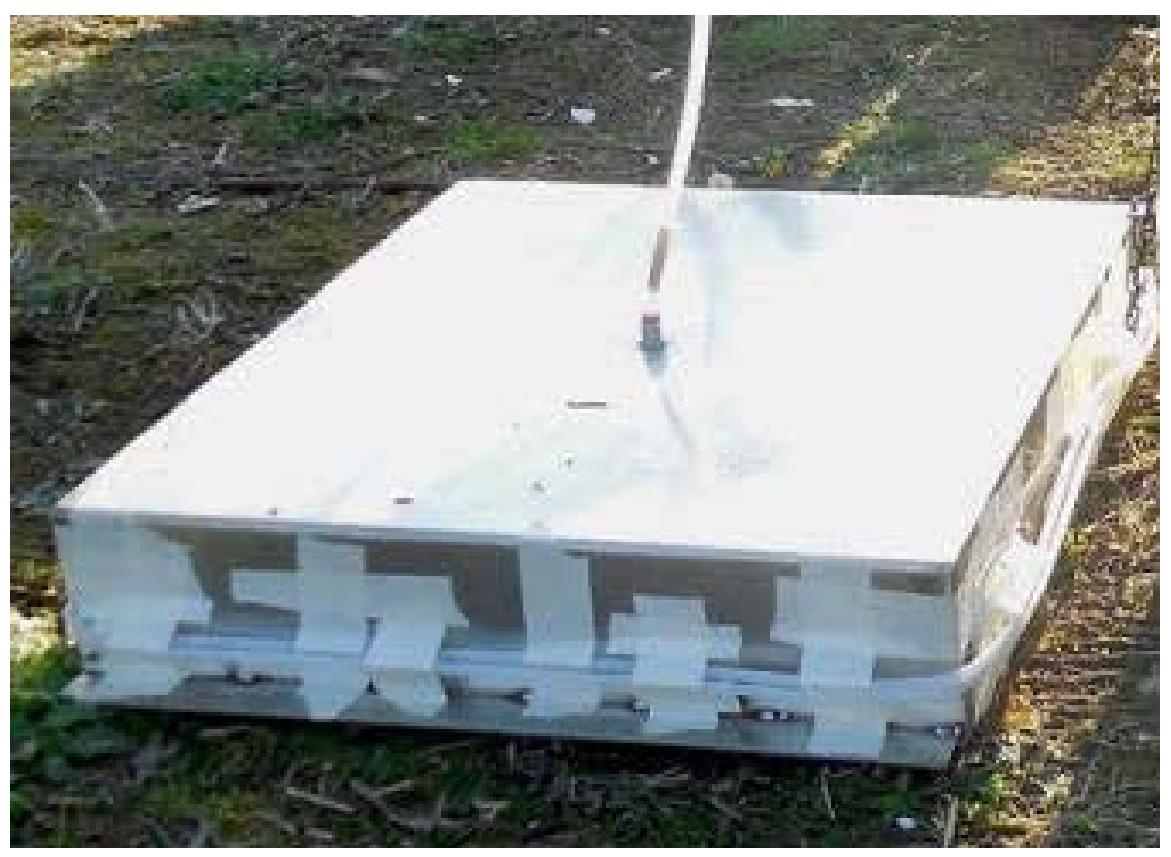

Figure 1. The LabOlf sampling device.

\subsection{Development of Odour Emission Factors (OEFs)}

In analogy with emission factors for other pollutants/chemical compounds, which relate the quantity of a pollutant released to the atmosphere to a given associated activity, Odour Emission Factors (OEFs) relate the quantity of odour emitted with the activity that generates the emission (Capelli et al., 2014). More in detail, such activity is given a proper index - called Activity Index (AI) - that is specific for the kind of source considered for the OEF definition. For a landfill, it is reasonable to assume as Al the entire landfill surface. In facts, it is acceptable to suppose that there is a proportionality correlation between the landfill surface and its odour emissions, as suggested in previous studies concerning this matter (Sironi et al., 2005). In the scientific literature, there are examples of OEF assessment procedures for some industrial facilities (Schauberger et al., 1999; Sironi et al., 2006; Capelli et al., 2009a), which in most cases consider the OEFs as fixed values constant in time. Newer researches discuss the need to consider the time variability as well (Hoff et al., 2006), when developing specific OEFs that should account for this crucial aspect, by means of proper functional dependencies (Schauberger et al., 2013). Therefore, the present study aims to try determining a specific OEF for landfill surfaces, capable also to account for variations over time. For clarity's sake, the emissions variation has been evaluated considering some key environmental parameters. As a 
matter of fact, there are some studies asserting that some meteorological parameters are correlated to LFG emissions from landfill surfaces, even though they mostly provide purely qualitative indications (McBain et al., 2005; Rachor et al., 2013). This is the reason why, in this project, in order to define an OEF specific for the site studied capable of accounting for these variations, the possibility of defining quantitative correlations between specific emitted LFG flow and several atmospheric parameters was investigated (see par.2.7).

In order to define the OEF it is necessary to assess the Odour Emission Rate (OER) for the inspected source; then the OEF can be obtained as the ratio between OER and Al (Capelli et al. 2009a), as shown in Eq.(1):

$$
O E F=\frac{O E R}{A I}
$$

Thus, once the source Al has been defined, the OEF assessment can be considered as a problem of evaluation of the source OER. In the following paragraphs, two different approaches for the definition of the odour emissions (OER) from landfill surfaces will be discussed.

\subsection{Approaches for quantifying odour emissions from landfill surfaces.}

Two possible approaches to estimate odour emissions from landfill surfaces are considered: a direct approach entailing odour concentration measures on site and an indirect approach relying on methane concentration measurements at the source coupled with a subsequent specific procedure to obtain the odour emissions (Capelli et al., 2015). The two options will be briefly summarized in this section.

The direct approach for the evaluation of odour emissions from landfill surfaces involves the direct measurement of odour concentration at the source, i.e. over the landfill surface. In the case of passive area sources, sampling is usually carried out by means of fluxed hoods, whereby sweep air is introduced in the hood and the sample collected at its outlet (Capelli et al., 2013b). The most widely used sampling devices for passive area sources are the so-called Wind Tunnels (Hudson and Ayoko, 2008), in which the sweep air flow is directional, thereby simulating the wind action over the surface to be sampled. However, since landfill surfaces cannot be considered as properly passive area sources as they are crossed by a low but non 
negligible flux and the emission is not really affected by the sweeping wind velocity, sampling is generally performed using other sampling devices such as flux chambers (Klenbusch, 1986). The reason for not using Wind Tunnels is mainly that there is no reason to believe that the odour emissions from landfill surfaces are affected by the wind speed as it is the case for the forced convection that occurs over passive area sources, so the simulation of the wind action on the surface seems useless. Moreover, on scarcely odorous sources Wind Tunnels tend to overestimate emissions (Capelli et al., 2015).

The indirect approach for the evaluation of odour emissions from landfill surfaces relies on the measurement of the $\mathrm{CH}_{4}$ concentration over the landfill surface. Also for this kind of measure, there is no worldwide univocally defined sampling procedure. Proposed methods range from static hoods (UK EA; 2010) to flux chambers (Klenbusch, 1986), resulting in quite different measurements depending on the used sampling device and methodology. For this reason, this study first involved the necessity to define a sampling procedure tailored for this peculiar type of source, exploiting a specifically designed Static Hood device (SH). As above mentioned (see par. 2.1), the device was realized developing the designs proposed by the UK EA (UK EA, 2010) and a German research group (Rachor et al., 2013). Since this approach is based on the quantification of the LFG emissions from the $\mathrm{CH}_{4}$ concentration measurements, the OER needs to be obtained indirectly by multiplying the emitted gas flow $\left(Q_{L F G}\right)$ rate by the LFG odour concentration ( $\left.\mathrm{CDD}_{\mathrm{OD}}\right)$, as shown in Eq.(2):

$$
O E R=Q_{L F G} * c_{o d, L F G}
$$

The odour concentration of the LFG emitted through the landfill surface was estimated by means of an ad hoc correlation investigated between $\mathrm{CH}_{4}$ concentration and odour concentration (see par. 2.5).

\subsection{Direct approach: odour sampling and direct OER evaluation}

As far as the sampling of odour on landfill surfaces is concerned - besides avoiding the use of wind tunnels, as previously mentioned, due to the peculiarity of the source type and its low odour emissivity - sampling by means of a specifically designed FC was preferred. The reason is mainly that, in general, sampling bags for olfactometry have capacities that are comparable to the volume of the sampling hood (in the present 
case about 1:4, i.e. 6 I of sampling bag volume vs. 25 I of internal hood volume). Therefore, olfactometric sampling from a static hood would imply a great perturbation of the system and significant depression in the chamber, which could affect the measure. Conversely, using a fluxed hood, the continuous introduction of sweep air inside the sampling hood reduces the effects of the sample withdrawal thus reducing the perturbation on the source. For this reason, in most cases odour measurements on landfill surfaces involve the application of a specifically designed Flux Chamber (Romain et al., 2008; McGinley, 1998).

In this research, the measure did not involve the device described in the US EPA guideline (Klenbusch, 1986), instead, the chamber described in the previous sections (see par. 2.1) was used. For this purpose, the upper tube is connected to an air cylinder providing a sweep airflow of $200 \mathrm{l} / \mathrm{h}$ that is introduced inside the hood, thereby mixing the inner air volume and the LFG emitted from the landfill surface. The American guideline (Klenbusch, 1986) suggests to perform at least 5 volume changes of the air inside the hood before performing the measurement, however, due to logistical reasons linked to the high neutral air consumption, in this study the number of volume changes was set to 1.5 , corresponding to a waiting time of 12 minutes. After this time has elapsed, a sample of the gaseous mixture inside the chamber is withdrawn and collected in a 6 I Nalophan ${ }^{\text {TM }}$ bag by means of a vacuum pump (Capelli e al., 2013b).

The odour concentration of the collected samples is measured in accordance to the European regulation EN $13725: 2003$, by means of Dynamic Olfactometry (CEN, 2003).

Dynamic Olfactometry relies on the identification, by the so-called analysis panel, of the "odour threshold", that is defined as the limit value where the odour is detected by the $50 \%$ of the examiners participating in the analysis. In order to bring the odour sample to this threshold it is necessary to use a proper dilution instrument, the Olfactometer: this machine allows diluting the odoriferous air sample to be analysed according to specific pre-set dilution ratios with neutral air, that is deodorised and dehumidified air treated by means of active carbon filtration and silica gel filtration. The number of dilutions required to bring the sample to its odour detection threshold is defined as the odour concentration of the sample and is expressed in terms of odorimetric units per cubic meter (in $\left.\mathrm{ou}_{\mathrm{E}} / \mathrm{m}^{3}\right)$. 
In the present study, the analyses involved an Odournet T08 Olfactometer equipped with 4 sniffing ports, remotely operated via PC; the apparatus and the olfactometric chamber are depicted in Fig. 2:

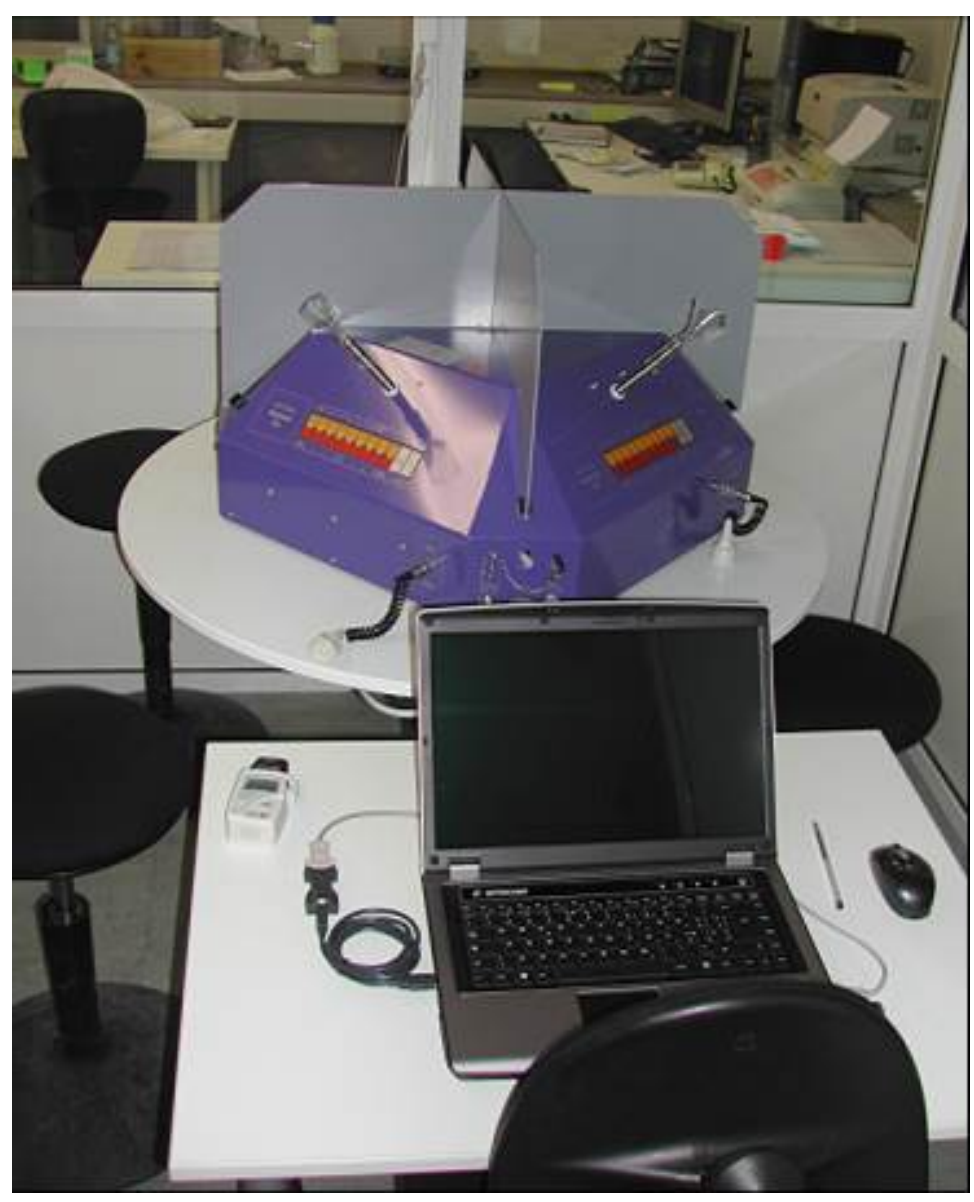

Figure 2. Olfactometer Odournet Model T08.

The odour concentration values obtained according to the above described procedure were used to establish a correlation between odour and methane concentrations in order to estimate the odour concentration of the LFG emitted from the landfill surface (see par. 2.5).

Once the odour concentration has been determined, in order to obtain the OER for the calculation of the OEF, it is first necessary to define the Specific Odour Emission Rate (SOER) as shown in Eq.(3):

$$
S O E R=\frac{Q_{\text {air }} \cdot c_{o d}}{A_{\text {base }}}
$$

where $C_{O D}$ is the odour concentration in $\mathrm{ou}_{\mathrm{E}} / \mathrm{m}^{3}$, $\mathrm{Q}_{\text {air }}$ is the sweep air flow in $\mathrm{l} / \mathrm{h}$ (equal to $200 \mathrm{I} / \mathrm{h}$ in this case) and $A_{\text {base }}$ is the hood base area in $\mathrm{m}^{2}$ (equal to $0.25 \mathrm{~m}^{2}$ ).

It is important to highlight that, due to the mixing of the LFG and the sweep air that takes place inside the hood, the odour concentration of the sample that is withdrawn from the hood depends on the sweep air 
flow rate: the higher the latter, the higher the dilution with the emitted LFG, thus giving lower odour concentrations. As a matter of fact, experimental studies prove that as long as the FC is operated with sweep air flows of 50-500 l/h, which do not interfere excessively with the emission from the surface, then the product of the odour concentration and the sweep air flow turns out to be constant (Capelli et al., 2014b).

The OER can then be obtained as the product of the SOER and the total emitting surface, i.e. the landfill surface $\left(A_{\text {landfill }}\right)$, as shown in Eq.(4):

$$
O E R=S O E R * A_{\text {landfill }}
$$

This gives that the OEF can be calculated as expressed in Eq.(5):

$$
O E F=\frac{O E R}{A I}=\frac{O E R}{A_{\text {landfill }}}=\frac{\text { SOER } * A_{\text {landfill }}}{A_{\text {landfill }}}=S O E R
$$

Thus, in this case where the Activity Index chosen for the definition of the OEF is the landfill surface, the OEF and the SOER coincide.

However, the application of this direct method for the evaluation of the OER from sources that are not highly odorous is likely to lead to an overestimation of the OER related to the emission of LFG from the landfill surface. In facts, odour concentrations that are typically measured on landfill surfaces are usually in the range of few tens-few hundreds of odour units per cubic meter. For this reason, if the OERs are evaluated by means of the direct approach, there is a significant risk of measuring odour concentration values that do not represent exclusively the characteristic odour of the LFG emitted through the landfill surface. It is likely to happen that at least a share of the sample concentration value is given by the socalled background odour. In this situation the background odour is intended as the odour of the landfill surface itself and of its components (e.g. soil, grass, sand...), odour that contributes to the overall concentration value of the collected sample, but is not representative solely of the emitted LFG odour.

This is why an approach for the evaluation of the odour emissions and the odour impact relying on the direct measure of the odour concentration at the source - for the peculiar case of low emissivity sources entails an intrinsic overestimation of the real emissions and the real impact. It is possible to find studies in 
the scientific literature that address this issue and prove this fact (Capelli et al., 2015), as well as literature references identifying typical background odour concentrations from 5 to $60 \mathrm{ou}_{E} / \mathrm{m}^{3}$ (UK Defra, 2010) or the intrinsic lower detection limit for Dynamic Olfactometry as 20-50 ou $/ \mathrm{m}^{3}$ (Capelli et al. 2013a).

For this reason, the indirect approach based on the measurement of the $\mathrm{CH}_{4}$ concentration over the landfill surface (see par. 2.5) is considered more representative of the effective LFG emissions with respect to the odour concentration measurement, and therefore it was preferred for the present research study for the estimation of the landfill OER.

\subsection{Indirect approach: development of a sampling system for the measurement of $\mathrm{CH}_{4}$ concentration}

As previously mentioned, this approach entails OER derivation from a measured value of $\mathrm{CH}_{4}$ concentration at the source, on the landfill surface. In the present study, the concentration was evaluated by means of a portable Crowcon GasTec Flame lonization Detector (FID) that exploits a hydrogen flame to burn hydrocarbons in the analysed air, quantifying the generated ions as a consequence of the combustion process. From this value, it is possible - by means of a proper mass balance as shown in the following - to obtain the methane emitted flow rate. From the specific characteristics of the cogeneration plant installed in the inspected landfill, it is known that the $\mathrm{CH}_{4}$ concentration in the produced LFG is roughly $50 \% \mathrm{v} / \mathrm{v}$. This allows to obtain from the $\mathrm{CH}_{4}$ emission $\left(\mathrm{Q}_{\mathrm{CH}}\right)$ the $\mathrm{LFG}$ emission $\left(\mathrm{Q}_{\mathrm{LFG}}\right)$, expressed in $\mathrm{I} / \mathrm{m}^{2} / \mathrm{h}$, necessary for the OEF evaluation (see par. 2.2). For the $\mathrm{CH}_{4}$ concentration measurement and $\mathrm{CH}_{4}$ emission assessment, theoretically, it is possible to use the adopted sampling device indifferently in static mode ( $\mathrm{SH}$, as indicated in the British guideline) or in fluxed mode (FC, as prescribed by the American guideline). However, based on a set of comparisons between the two methods carried out in the field during the first months of this research project, it was possible to observe that they produce substantially the same results. Therefore, it was decided to proceed with the research in the field adopting solely the static mode, due to logistical reasons linked to the high neutral air demand required for the fluxed mode. 
The sampling procedure defined for the $\mathrm{CH}_{4}$ concentration measure by means of the $\mathrm{SH}$, provides that the hood is positioned over the landfill terrain for a certain time that was defined equal to 10 minutes, period in which the LFG emitted from the surface accumulates inside the chamber. After this time, the analysis is performed by connecting the FID to the hood outlet. The FID sucks about $1.06 \mathrm{I} / \mathrm{min}$ of air for 2 minutes; after that, the $\mathrm{CH}_{4}$ concentration is visualized on the instrument display. The sampling methodology here presented relies on two fundamental hypothesis, which have been verified by means of a set of tailored computational fluid dynamics (CFD) simulations exploiting the software ANSYS Fluent ${ }^{\circledR}$. The first hypothesis is that the $\mathrm{CH}_{4}$ concentration growth is linear over time during the established positioning period (i.e. 10 minutes). This time is not a random or casual choice, on the contrary it is based on considerations concerning the hood dimensions and the expected emitted LFG fluxes. In previous studies (Capelli et al., 2015), it was concluded that a good positioning period is 10 minutes: this time is short enough with respect to the expected time in which the asymptote is reached, that the linear growth hypothesis should hold true. In facts, even though the concentration has a plateau asymptotic trend, with a constant value at infinite times, such trend in the initial section (i.e. in the first minutes, that for the studied case is $t<20$ min) can be well approximated with a linear trend.

The second hypothesis is that the measured concentration with the FID is representative of the average concentration inside the hood. This assumption as well was confirmed by means of a specific CFD study.

Based on these assumptions, it is possible to evaluate the specific LFG flux emitted from the landfill surface $\left(\widehat{Q}_{L F G}\right)$ by means of a simple material balance on the sampling hood as shown in Eq.(6):

$$
V \cdot \frac{d \bar{C}_{C H 4}}{d t}=\hat{Q}_{L F G} \cdot A_{\text {base }} \cdot c_{C H_{4}, L F G}
$$

where $V$ is the volume of the hood equal to $25 l, \frac{d \bar{C}_{C H 4}}{d t}$ is the average $\mathrm{CH}_{4}$ concentration variation inside the hood over time, $\widehat{Q}_{L F G}$ is the specific LFG flow, i.e. the LFG emitted from the landfill surface inside the hood $l / \mathrm{m}^{2} / \mathrm{h}, \mathrm{A}_{\text {base }}$ is the hood base area $\left(0.25 \mathrm{~m}^{2}\right)$, and $c_{\mathrm{CH}_{4}, L F G}$ is the concentration in the pure LFG equal to 500 '000 ppm. Thus, assuming that the $\mathrm{CH}_{4}$ concentration inside the hood is zero at time zero and has a linear growth over time, and that the $\mathrm{CH}_{4}$ concentration that is measured by means of the FID is equal to 
the average $\mathrm{CH}_{4}$ concentration inside the hood $\bar{c}_{\mathrm{CH}_{4}}$, then the specific LFG flow rate can be calculated integrating Eq. (6) between $\left(t_{0}=0\right)$ and $\left(t_{0}+\Delta t\right)$. The obtained expression is reported in Eq. (7):

$$
\hat{Q}_{L F G}=\frac{c_{C H_{4}, m i s} \cdot V}{c_{C H_{4}, L F G} \cdot \Delta t \cdot A_{\text {base }}}
$$

where $c_{\mathrm{CH}_{4}, \text { mis }}$ is the $\mathrm{CH}_{4}$ concentration measured by means of the FID (ppm).

In this case the OEF, i.e. the SOER can be calculated as expressed in Eq.(8):

$$
S O E R=\widehat{Q}_{L F G} \cdot c_{O d, L F G}
$$

where $c_{O d, L F G}$ is the odour concentration of the LFG emitted from the landfill surface, which needs to be determined. This value is not directly measurable, and similar values are not easily found in the scientific literature. As a matter of fact, some studies refer to the odour concentration of the pure LFG, which is typically measured directly in the LFG extraction wells / collection system. These odour concentration values are typically around $900^{\prime} 000 \mathrm{ou}_{\mathrm{E}} / \mathrm{m}^{3}$ (Sarkar and Hobbs, 2002; Sironi et al., 2005), but such values are likely to be significantly higher than the odour concentration of the LFG emitted through the landfill surface. This is because the LFG crossing the landfill cover will likely undergo partial degradation/oxidation, thereby reducing its odour concentration, which generally depends on the type of cover and its thickness (Capanema et al., 2014).

For this reason, it was decided to estimate the $c_{O d, L F G}$ assuming that there should be a linear proportionality between the odour concentration and the $\mathrm{CH}_{4}$ concentration measured over the landfill surface. Based on this assumption, if the equation describing this correlation can be established, then it is possible to estimate the $c_{o d, L F G}$ as the odour concentration that corresponds to the $\mathrm{CH}_{4}$ concentration of LFG, i.e. 500 '000 ppm.

The adopted method therefore consisted in an attempt to build a correlation between the measured cod values with the direct method (see par. 2.4) and the corresponding $\mathrm{CH}_{4}$ concentration values measured with the indirect method (see par. 2.5), by means of a specific set of measurement campaigns on site evaluating at the same time $\mathrm{CH}_{4}$ concentration (with a FID) and odour concentration (through Dynamic 
Olfactometry). The correlation was constructed including all gathered data over several months, from March 2014 to October 2015.

\subsection{The site}

The landfill chosen for the experimental campaigns is located in Northern Italy and has an extension of $250^{\prime} 900 \mathrm{~m}^{2}$. The site is subdivided in six allotments organized in cells, with just one still operational. The landfill officially opened in 1993 and presents a MSW storage capacity of roughly 6' $200^{\prime} 000 \mathrm{~m}^{3}$. The landfill is equipped with an LFG collection and management system designed to minimize the emissions and valorise the produced biogas by means of a cogeneration plant capable of producing thermal and electrical power. Moreover, a leachate collection system is also present on site, with 2 collection tanks for the closed allotments and 2 collection tanks for the operational allotments; the leachate then undergoes a pretreatment aimed to lower its pollutant load and odour potential, before being sent to a waste water treatment plant. In this landfill the leachate recirculation on closed allotments is not performed. There is also a waterproofing of the allotments thanks to polymeric geo-membranes. The covering of the cells is realized with waterproof clay layers.

The experimental campaigns on site have been numerous with a frequency of 2 times per week for a grand total of 40. The campaigns went on since December 2014 till October 2015 and involved measurements on different points on closed allotments. The sampling points considered have been 4 from December 2014 to March 2015, when 2 of these points were discarded for being basically non-emissive. In March 20153 new points have been identified; therefore from March 2015 to October 2015 the points considered for the measurements have been 5 . The measures always took place at the same time of day, roughly around 11 a.m. Moreover, the campaigns excluded days either too humid or cold or rainy, since in these weather conditions it was observed that the emissions are always zero.

\subsection{Correlating LFG emissions and meteorological parameters}


In order to investigate the existence of a correlation between LFG surface emissions and the meteorological conditions the atmospheric data for the months of the campaigns and the area studied have been gathered from the Regional Environmental Protection Agency (ARPA). Specifically, the parameters requested are: rainfalls in $\mathrm{mm}$, atmospheric temperature in ${ }^{\circ} \mathrm{C}$, atmospheric pressure in $\mathrm{hPa}$, wind speed in $\mathrm{m} / \mathrm{s}$, wind direction in ${ }^{\circ}$, relative air humidity in $\%$, global solar radiation in $\mathrm{W} / \mathrm{m}^{2}$. Furthermore, another variable was considered, that is the soil relative humidity in $\%$, that was obtained empirically collecting a soil sample on site, weighting it, drying it in a laboratory heater, re-weighting it and thus computing the relative humidity as shown in Eq.(9):

$$
R H_{\text {soil }}=\frac{m_{\text {soil }}^{\text {wet }}-m_{\text {soil }}^{\text {dry }}}{m_{\text {soil }}^{\text {wet }}}
$$

\section{RESULTS AND DISCUSSION}

\subsection{Assessment of the mean specific flux of the emitted LFG}

As previously mentioned, the development of an OEF by means of the "indirect approach", requires estimating the specific flux of the LFG emitted through the landfill surface, which can be obtained from the data gathered during the experimental campaigns on site, as described in par. 2.6.

The results obtained in the 40 experimental campaigns performed - from December 2014 to October 2015

- are reported in Tab. 1, where, for each considered sampling point, both $\mathrm{CH}_{4}$ concentrations in ppm (evaluated with a FID according to the procedure described in par. 2.5) and the respective specific flow rates of the emitted LFG in $1 / \mathrm{m}^{2} / \mathrm{h}$ are indicated. The LFG specific flux values have been evaluated thanks to a material balance on the chamber according to Eq.(7) (see par. 2.5).

The grey cells indicate those measurements for which the measured $\mathrm{CH}_{4}$ concentration resulted equal to 0 . It is possible to observe that the number of null measurement is significant with respect to the total. It was noticed that null measurements mainly occur after significant rainfalls, which make the terrain so wet that there is a sort of "cork effect" inhibiting the emission of LFG into the atmosphere. The presence of empty 
cells for points 1 and 2 from March 2015 is related to the fact that these two points were abandoned for monitoring purposes because of their too low emissivity with respect to the others, as previously mentioned in par. 2.6. 


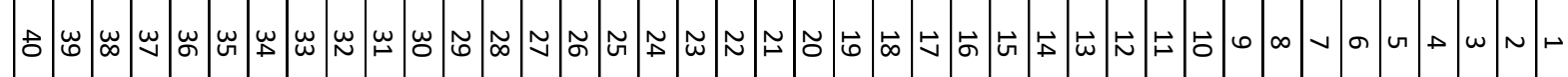

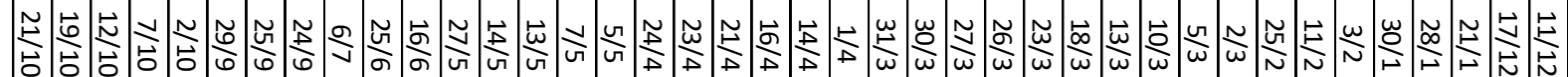

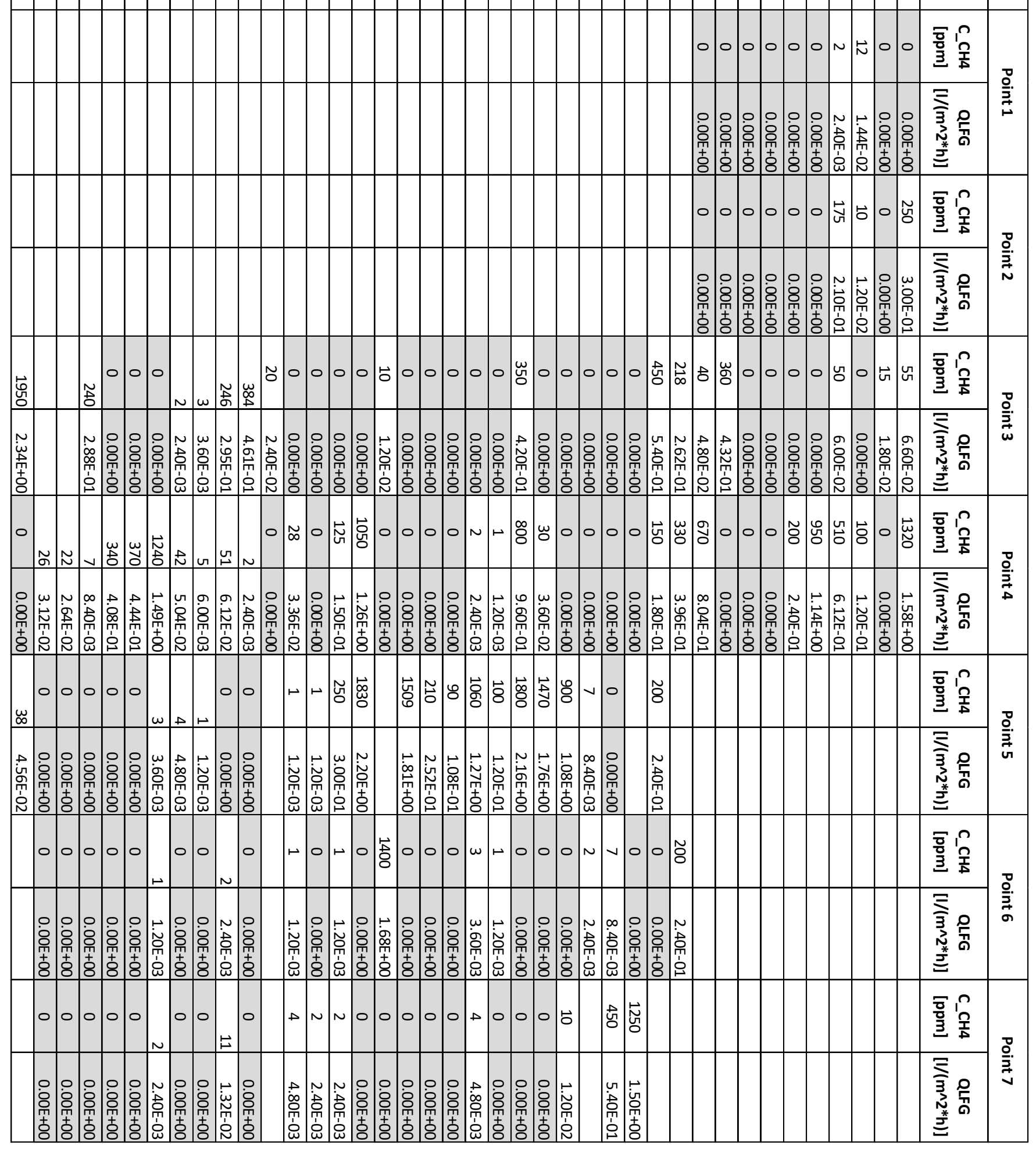

Table 1. Results of the experimental campaigns on the studied landfill: $\mathrm{CH} 4$ concentration values (in ppm) and specific fluxes (in $\mathrm{l} / \mathrm{m} 2 / \mathrm{h}$ ) relevant to the 7 monitored points. 
For a better visualization and understanding of the results, it is possible to display the obtained LFG flux data in a plot (see Fig. 3 ) where on the abscissae there is the identification number of the measurement campaign - progressive numeration, from 1 to 40 - and on the ordinates the specific flux value in $\mathrm{I} / \mathrm{m}^{2} / \mathrm{h}$. The graph reports also the average value for the emitted LFG flux - for the considered landfill - obtained as an arithmetic mean of all values reported in Tab. 1 for the 7 considered points, excluding the zeros. Representing the average value of the flux as the arithmetic mean of the computed fluxes is chosen as criterion as it is in accordance with the guidelines provided by the UK Environment Agency (UK EA, 2010).

The obtained mean value is equal to $0.39 \mathrm{I} / \mathrm{m}^{2} / \mathrm{h}$ with a standard deviation of $0.61 \mathrm{I} / \mathrm{m}^{2} / \mathrm{h}$ and a median value of $0.055 \mathrm{I} / \mathrm{m}^{2} / \mathrm{h}$. Such values call for a short dissertation; in facts, it is possible to see how the arithmetic mean value and the median value are almost one order of magnitude apart. This fact is due to a certain variability of the flux values obtained with a majority of rather low values but also a share of rather high ones: actually, it is possible to have a better feeling of the matter looking at another statistical indicator, the geometrical mean, which is equal to $0.051 \mathrm{l} / \mathrm{m} 2 / \mathrm{h}$.

The arithmetic mean value of $0.39 \mathrm{l} / \mathrm{m}^{2} / \mathrm{h}$ for the specific emitted LFG flux was then used to compute the OEF, multiplying the mean LFG flux by the odour concentration of the LFG emitted through the landfill surface - as explained extensively in par. 2.2 - according to the procedure described in the previous section. 


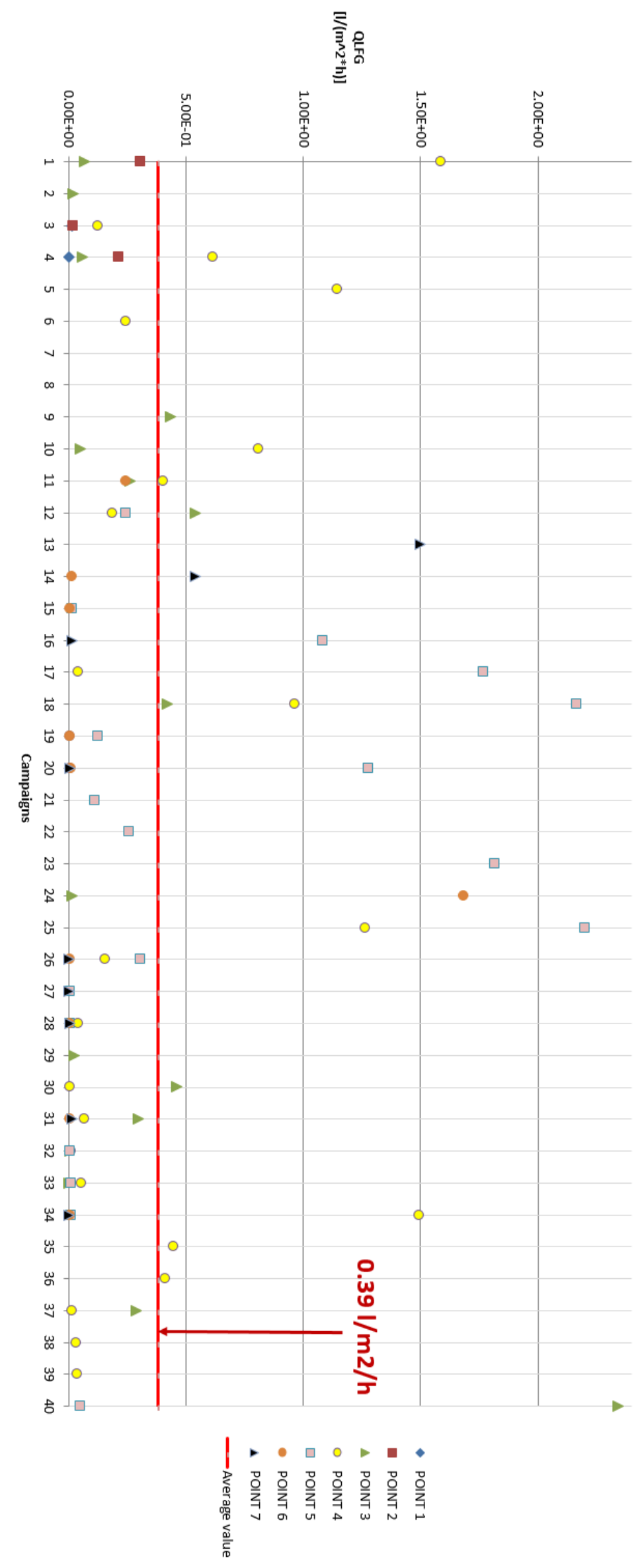

Figure 3. Graphical representation of the results of the experimental campaigns (specific LFG flow rates in $1 / \mathrm{m}^{2} / \mathrm{h}$ ) 
In order to make an evaluation of the obtained mean LFG flux, from the experimental campaigns, it is possible to compare it with similar data found in the scientific literature. It is possible to find very different values for the emitted LFG flux in scientific papers, depending on where the studied landfill is located and when it was designed/opened.

As example, in a 2001 article by Park et al., it is provided a description of an investigation concerning the LFG superficial emissions from a landfill located in South Korea, namely the Sudokwon MSW landfill (Park et al., 2001). The landfill is located near the Inchon City area in South Korea. The studied site in 2001 was subdivided in 17 allotments and is structured in cells and is designed to have 8 lifts of wastes: each lift is 5 $\mathrm{m}$ high, with an intermediate cover $0.7-0.5 \mathrm{~m}$ thick for a total height of $40 \mathrm{~m}$. The cover is $65 \%$ sand, $22 \%$ silt, $13 \%$ clay. The landfill is also equipped with a LFG collection and disposal system. In particular, the LFG collection system consists of gas collectors placed at all even numbered lifts, extraction wells and monitoring probes, a pipeline network conveying the captured LFG to a flare. The emitted LFG flux was assessed by the authors and resulted equal to $160 \mathrm{I} / \mathrm{m}^{2} / \mathrm{h}$ in the winter and $900 \mathrm{I} / \mathrm{m}^{2} / \mathrm{h}$ in the summer. It is possible to see that these values are significantly higher than the values presented in this research work. This discrepancy may be explained considering that there are many factors affecting the LFG surface emissions, thus different landfills with different characteristics will yield different flux values. First, the efficiency of the LFG collection system plays a crucial role, since the emission is simply the production minus the collected share. It has to be further underlined that the two landfills are located in different countries and different continents, therefore have different design criteria and follow different legislations. Another aspect having a great influence on LFG surface emissions is the adopted landfill cover: LFG and odour emissions can be significantly reduced by designing a suitable cover, i.e. realizing a cover with an appropriate material (Capanema et al., 2014; Solan et al., 2010; Hurst et al., 2005), waterproof and of sufficient height. In the Italian landfill, the cover has no waterproof cloth but the clay of the cover provides a certain degree of waterproofing, limiting LFG emissions. Finally, another important aspect that determines LFG generation is the quality of the landfilled waste, considering that biodegradable waste (e.g., organic waste) has a higher methane generation potential (Alexander et al., 2005), thus resulting in a 
higher LFG production. It is possible to consider that landfill sites located in the same geographical region are normed by similar laws and the wastes treated therein are likely to have similar characteristics. In regions subjected to different regulations, the landfilled wastes may have very different characteristics and possibly have higher LFG production potentials. As a matter of fact, in developing countries, waste pretreatments is up to now not significantly widespread and the unprocessed waste - typically characterized by a higher organic content - is landfilled directly, thus giving increased LFG production rates. In order to carry out a proper comparison with the outcomes of the present study, it is necessary to consider an analogue landfill to the one inspected, located possibly in northern Italy, which is likely to have both landfilled waste quality and landfill management operations that are similar to those of the studied landfill. A similar datum is available and it can be found in a 2014 scientific paper by Palmiotto et al., where the obtained surface LFG flux is equal to $0.2 \mathrm{l} / \mathrm{m}^{2} / \mathrm{h}$ (Palmiotto et al., 2014): it is easy to see that this value is very much comparable with the one provided in the present project.

\subsection{Assessment of the emitted surface LFG odour concentration and development of the OEF}

As previously explained in par. 2.5 , in order to estimate the odour concentration of the LFG emitted through the landfill surface, the existence of a linear correlation between methane concentration and the odour concentration in the emission was theorized (see par. 2.4). For the quantitative determination of this relationship all data gathered from March 2014 to October 2015 have been considered. The complete dataset was refined by excluding odour concentration values lower than $80 \mathrm{ou} / \mathrm{m}^{3}$, since most likely, at least a share of the sample's concentration value is given by the so-called background odour, intended as the odour of the landfill surface itself and of its components (e.g. soil, grass, sand...). In facts, in some regulations there is an explicit indication on what should be considered as the "background odour threshold" (UK Defra, 2010). As an example, the regulation adopted in the Region of Lombardy sets this threshold at $80 \mathrm{ou}_{\mathrm{E}} / \mathrm{m}^{3}$, in order to distinguish what is considered air and what is not (D.G.R. Regione Lombardia, 2012). The considered values are listed in Tab. 2: 


\begin{tabular}{|c|c|c|}
\hline Date & C_CH4 & C_OD \\
\hline [dd/mm/yyyy] & [ppm] & [ou/m^3] \\
\hline $05 / 03 / 2014$ & 280 & 228 \\
\hline $05 / 03 / 2014$ & 110 & 144 \\
\hline $05 / 03 / 2014$ & 130 & 136 \\
\hline $05 / 03 / 2014$ & 60 & 161 \\
\hline $18 / 04 / 2014$ & 110 & 228 \\
\hline $18 / 04 / 2014$ & 70 & 85 \\
\hline $18 / 04 / 2014$ & 40 & 121 \\
\hline $21 / 04 / 2014$ & 19 & 144 \\
\hline $21 / 04 / 2014$ & 20 & 128 \\
\hline $18 / 07 / 2014$ & 150 & 136 \\
\hline $23 / 09 / 2014$ & 150 & 342 \\
\hline $10 / 11 / 2014$ & 12 & 127 \\
\hline $18 / 11 / 2014$ & 14 & 143 \\
\hline $18 / 11 / 2014$ & 6 & 91 \\
\hline $25 / 11 / 2014$ & 10 & 215 \\
\hline $25 / 11 / 2014$ & 56 & 114 \\
\hline $11 / 12 / 2014$ & 888 & 384 \\
\hline $17 / 12 / 2014$ & 2 & 136 \\
\hline $28 / 01 / 2015$ & 540 & 161 \\
\hline $02 / 03 / 2015$ & 340 & 228 \\
\hline $05 / 03 / 2015$ & 1 & 287 \\
\hline $10 / 03 / 2015$ & 455 & 242 \\
\hline $24 / 09 / 2015$ & 2 & 152 \\
\hline $24 / 09 / 2015$ & 42 & 171 \\
\hline $07 / 10 / 2015$ & 240 & 114 \\
\hline
\end{tabular}

Table 2. Odour and methane concentration values measured on the studied landfill surface from March 2014 to October 2015

From the data in Tab. 2 , it is possible to obtain a plot having on the $x$-axis the methane concentration values expressed in ppm and on the $y$-axis, the odour concentration values expressed in $\mathrm{ou}_{\mathrm{E}} / \mathrm{m}^{3}$, as shown in Fig. 4: 


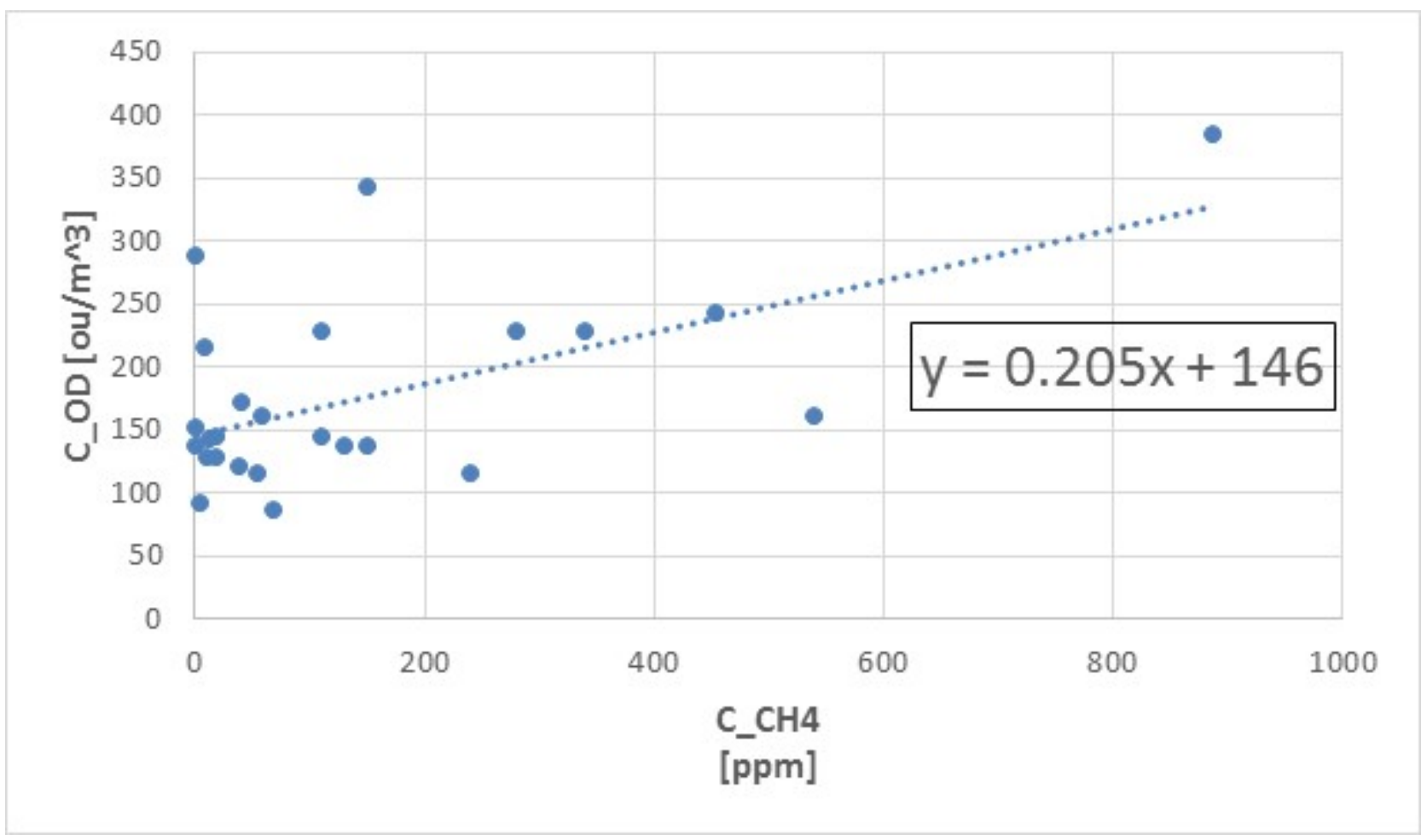

Figure 4. The correlation between odour and methane concentration

In Fig. 4 the interpolation line that approximates the experimental values is also reported. For similar correlations, often the correspondence of two different datasets is evaluated with respect to the line $x=y$ starting from the origin. However, in this case, it was decided to trace an interpolation line that does not passes through the origin, which would represent the point at which both the methane concentration and the odour concentration are equal to zero. As already discussed, the zero odour concentration point does not exist due to the existence of the background odour. Instead, the interception of the interpolation line with the $y$-axis, which turned out to be equal to $146 \mathrm{ou}_{\mathrm{E}} / \mathrm{m}^{3}$, represents the odour concentration corresponding to $\mathrm{CH}_{4}$ concentration equal to zero. This number assumes a physical meaning and it may be considered as the characteristic odour concentration of the landfill surface itself, in absence of LFG emissions, i.e. the background odor (see par. 2.4).

The equation of this interpolation is reported in Eq. (10):

$$
y=0,21 x+146
$$


Where $\mathrm{x}$ is the $\mathrm{CH}_{4}$ concentration in ppm and $\mathrm{y}$ is the corresponding odour concentration in $\mathrm{ou}_{\mathrm{E}} / \mathrm{m}^{3}$. Since the $\mathrm{CH}_{4}$ concentration in the pure LFG emitted through the landfill surface is roughly $50 \% \mathrm{v} / \mathrm{v}$, i.e. $500^{\prime} 000$ ppm, by inserting this value in Eq.(10), it is possible to obtain the odour concentration of the emitted LFG, representative of the site inspected. In this case, the obtained value is $105^{\prime} 000 \mathrm{ou}_{\mathrm{E}} / \mathrm{m}^{3}$. This datum has a great significance, especially because similar data can hardly be found in the scientific literature, in facts, usually the values reported in scientific papers do not refer to the LFG emitted through the landfill surface but are referred to the pure LFG sampled directly at the extraction wells, which has a much higher odour concentration. This is due to the fact that it does not undergo the bio-reduction process that occurs while the LFG crosses the landfill cover (Capanema et al., 2014; Solan et al., 2010; Hurst et al., 2005).

Besides the literature data, the most significant datum that can be used in order to evaluate the extent of this bio-reduction is the odour concentration of the pure biogas collected at the extraction wells of the examined landfill. For this purpose, a total of 8 LFG samples were collected at 2 different extraction wells during the 4 seasons of the investigation, giving an average odour concentration value of $300^{\prime} 000 \mathrm{ou} / \mathrm{m}^{3}$, which is three times the concentration obtained from the LFG emitted into the atmosphere from the landfill surface. The difference between the two values of $C_{O D}$ proves what was discussed above, that is the bio-reduction effect that is observed as the LFG crosses the landfill surface resulting in a significant reduction of its odour concentration. The found reduction in LFG odour concentration - about $65 \%$ - is reasonable if compared with what was found by several other authors (Sadasivam and Reddy, 2014); the actual values vary according to cover characteristics, landfill design, soil composition and moisture content.

At this point, with the specific flow rate of the emitted LFG and the respective $C_{O D}$, it is possible to apply the formulas presented in par. 2.7 and compute the Specific Odour Emission Rate (SOER) that coincides with the OEF, given that the landfill surface is assumed as AI. The OEF is then computable as the product between the mean specific LFG flux emitted through the surface - resulting from the experimental campaigns, equal to $0.39 \mathrm{l} / \mathrm{m}^{2} / \mathrm{h}$ - and its odour concentration, equal to $105^{\prime} 000 \mathrm{ou}_{\mathrm{E}} / \mathrm{m}^{3}$. Therefore, the OEF can be evaluated as shown in Eq.(11): 


$$
O E F=S O E R=\hat{Q}_{L F G} \cdot c_{o d, L F G}=0.39 \cdot 10^{-3} \frac{m^{3}}{m^{2} h} \cdot 105000 \frac{o u_{E}}{m^{3}}=0.0113 \frac{o u_{E}}{m^{2} s}
$$

This value is considerably lower than those published in previous works (Sironi et al., 2005) that were likely to be overestimated due to both the sampling method and the evaluation procedure, which could be refined thanks to the most recent developments of the research in this field. For this reason, the SOER of $0.0113 \mathrm{ou}_{\mathrm{E}} / \mathrm{m}^{2} / \mathrm{s}$ should be considered as the correct value to represent the OEF for the estimation of odour emissions from a landfill surface, thereby referring to the closed portion of the landfill.

\subsection{Refinement of the OEF investigating a correlation between LFG emissions and meteorological data}

Before analysing the gathered data representative of the studied landfill, and trying to correlate them with the proper meteorological data, the first step was an extensive literature research in order to be aware of what has already been done in this area. This overview allows for a critical and meaningful analysis of the data and the outcomes, making it possible to perform a comparison between the results presented in the literature and those here produced.

\begin{tabular}{|l|l|l|}
\hline \multicolumn{1}{|c|}{ Meteor. Parameter } & \multicolumn{1}{|c|}{ Correlation Type } & \multicolumn{1}{c|}{ Authors' Hypothesis } \\
\hline Atmospheric Pressure (P) & $\begin{array}{l}\text { Negative Correlation: P increases and } \\
\text { LFG flow decreases (Reinhart et al., } \\
\text { 1992; McBain et al., 2005) }\end{array}$ & Landfill “respiration" \\
\hline Temperature (T) & $\begin{array}{l}\text { Positive Correlation (a): T increases } \\
\text { and LFG flow increases (Park et al., } \\
\text { 2001) }\end{array}$ & $\begin{array}{l}\text { (a) Waste decomposition process is } \\
\text { enhanced } \\
\text { (b) Temperature governs microbial CH }\end{array}$ \\
& $\begin{array}{l}\text { Negative Correlation (b): T increases } \\
\text { and LFG flow decreases (Rachor et al., }\end{array}$ & $\begin{array}{l}\text { oxidation because chemical processes in } \\
\text { the cells are faster at greater energy }\end{array}$ \\
\hline
\end{tabular}




\begin{tabular}{|c|c|c|}
\hline & 2013) & supplies (i.e during the warm season) \\
\hline Soil Humidity (U) & $\begin{array}{l}\text { Positive Correlation (a): U increases } \\
\text { and LFG flow increases (Rachor et al., } \\
\text { 2013) } \\
\text { Negative Correlation (b): U increases } \\
\text { and LFG flow decreases (Rachor et al., } \\
\text { 2013) }\end{array}$ & $\begin{array}{l}\text { (a) } \mathrm{CH}_{4} \text { production is enhanced in a } \\
\text { moist environment and } \mathrm{CH}_{4} \text { oxidation is } \\
\text { disadvantaged by lack of } \mathrm{O}_{2} \text { (pores } \\
\text { occupied by } \mathrm{H}_{2} \mathrm{O} \text { ) } \\
\text { (b) } \mathrm{CH}_{4} \text { oxidation is favored, more } \\
\text { favorable environment for metanotroph } \\
\text { bacteria }\end{array}$ \\
\hline Wind Velocity (v) & $\begin{array}{l}\text { Positive Correlation (a): v increases } \\
\text { and LFG flow increases (McBain et al., } \\
\text { 2005) } \\
\text { Negative Correlation (b): v increases } \\
\text { and LFG flow decreases (Rachor et al., } \\
\text { 2013; Reinhart et al., 1992) }\end{array}$ & $\begin{array}{l}\text { (a) Diffusive resistance is lowered, the } \\
\text { boundary layer thickness decreases } \\
\text { (b) Wind velocity influences the } \\
\text { pressure value on soil surface, P } \\
\text { increases }\end{array}$ \\
\hline Rainfalls (p) & $\begin{array}{l}\text { Negative Correlation: } p \text { increases and } \\
\text { LFG flow decreases (Rachor et al., } \\
\text { 2013) }\end{array}$ & $\begin{array}{l}\text { Cork effect, water prevents LFG from } \\
\text { going into the atmosphere }\end{array}$ \\
\hline
\end{tabular}

Table 3. Summary of the main findings about correlations of LFG emissions from landfills with atmospheric variables in scientific literature.

Tab. 3 summarizes the principal findings emerged from the literature research. The correlations presented in the considered scientific papers and the respective explanations/discussions, as it is possible to see, are purely qualitative and often contradictory. As an example, some authors (Park et al., 2001) provide a positive correlation between atmospheric temperature and LFG emissions, stating that as temperature increases also LFG emission increases, explaining that higher temperatures enhance the waste decomposition process and the LFG production. On the contrary, other authors (Rachor et al., 2013) suggest a negative correlation with temperature, i.e., observing an emission decrease as temperature 
increases, explaining that temperature governs microbial $\mathrm{CH}_{4}$ oxidation because chemical processes in the cells are faster at greater energy supplies, therefore during the warmer seasons the $\mathrm{CH}_{4}$ oxidation is enhanced and the emissions reduced. Looking at another variable, some researchers (McBain et al., 2005) believe that wind velocity is positively correlated to LFG emissions: as wind velocity increases the emissions increase, because the soil to air diffusive resistance is reduced by higher speeds since they tend to diminish the boundary layer thickness. However, other scientists underline that there is a negative correlation between wind velocity and LFG emissions (Rachor et al., 2013; Reinhart et al., 1992): if the wind velocity increases the LFG emissions decrease, as wind velocity affects the pressure field above the surface and higher velocities cause an increased pressure on the surface thus reducing the LFG entering the atmosphere.

One reason for which no quantitative or clear correlations were found in the above mentioned studies might be connected to the type of atmospheric data considered. Almost all available literature papers consider "punctual" values for the atmospheric variables, i.e. referred to the hour of the measure. However, considering the diffusion dynamics inside the landfill body, it seems difficult that the meteorological data (e.g., atmospheric pressure, air temperature) measured at the moment of the sampling might directly and immediately affect the LFG production and emission from the landfill surface. For this reason, it is hard to expect some kind of precise correlation between the LFG flux measured over the landfill surface and the instantaneous meteorological conditions. Based on this argument, trying to relate the measured emission with closer but previous data, or with data trends, appears more reasonable. Therefore, it was decided to investigate the existence of a correlation between the measured LFG flux data and the meteorological parameters looking at trends in terms of gradients and time-averaged values. In order to prove the validity of the hypothesis made, many cross-referenced studies have been carried out, for all the considered atmospheric variables, as discussed in par. 2.6. In the following there will be a short dissertation on the findings emerged from this process.

In order to verify the existence of some sort of correlation between the LFG emission from landfill surface and the meteorological variables, the obtained emitted flux was plotted against each considered 
parameter. These graphs provided hints on which variables should be excluded from further inquiries, since unrelated to the emissive phenomenon. As example, wind velocity and wind direction resulted hardly significant because the hood adopted for the experimental campaigns on site serves the specific purpose of isolating a portion of the landfill were is deposed, making the action of the wind irrelevant. The air temperature also resulted not very relevant, probably because the waste decomposition process is at an advanced stage, where the relative small temperature variations play an only minor role on the kinetics of the process; in facts, it is necessary to bear in mind that sampling took place on closed allotments that finished operations several years ago. Air humidity as well was deemed irrelevant and this confirms what emerged in the preliminary studies: air humidity does not affect LFG surface emissions, both because there are no mentions in that sense in the scientific literature and because there is not a thing that would justify the existence of such correlation. Concerning rainfalls, they have also been excluded from further research because it was thought more meaningful to consider directly the soil humidity since it reflects the rain trends and is closely linked to the phenomena taking place inside the landfill body.

In the end, the meteorological variables thought most significant for the LFG emissions are the atmospheric pressure and the soil humidity. Ongoing studies are trying to identify more complex indicators, such as the irradiation index $(\mathrm{L})$ that is the ratio between the actual Solar Irradiation value $(R)$ and the corresponding maximum value $\left(R_{\max }\right)$. In addition, additional composed indicators are being evaluated, obtained as the product or the ratio between single parameters: e.g. Solar Irradiation * Atmospheric Pressure, Solar Irradiation / Atmospheric Pressure...

Concerning atmospheric pressure, from the findings emerged during the literature research, it was identified a phenomenon called "landfill respiration": it was defined in order to provide an explanation of the weak negative correlation between pressure and emissions that was observed in several occasions. According to the phenomenon when pressure increases the LFG is "pushed" into the soil and the emission is therefore reduced; when the pressure decreases on the contrary the LFG encounters smaller resistances and the emission increase. However, this explanation does not consider that the real pressure differences that can be observed are very little and cannot affect significantly the emissions. In order to investigate the 
matter, the daily and monthly trends of the atmospheric pressure are inspected and are compared with the measured emission data. It emerged that there are no direct correlations. Then, the emissions were compared with the pressure gradients over the 3 and the 6 hours before each campaign; in this case as well, no clear correlation could be identified. The only correlations that look promising are those between the LFG emissions and the pressure value averaged over the 24 and the 48 hours preceding the measure. Anyhow, from what emerged so far, it looks like there is a positive correlation between LFG emissions and average pressure (see Fig. 5), differently from the indications found in the scientific literature. Such a correlation may be explained considering that the mean pressure is really an indicator for other variables as air temperature, solar radiation and rainfalls: decreasing pressure indicates bad weather, therefore lower emissions, while increasing pressure indicates good weather, therefore higher emissions. This fact corroborates the idea that new "complex" atmospheric indicators should be researched, indicators that combine these "simpler" indicators.

Fig. 5 and Fig. 6 show the plots depicting the trends of the LFG emissions with the considered parameters, i.e. the time-averaged pressures, referred to one of the sampled points (Point 4) which hint at a positive correlation.

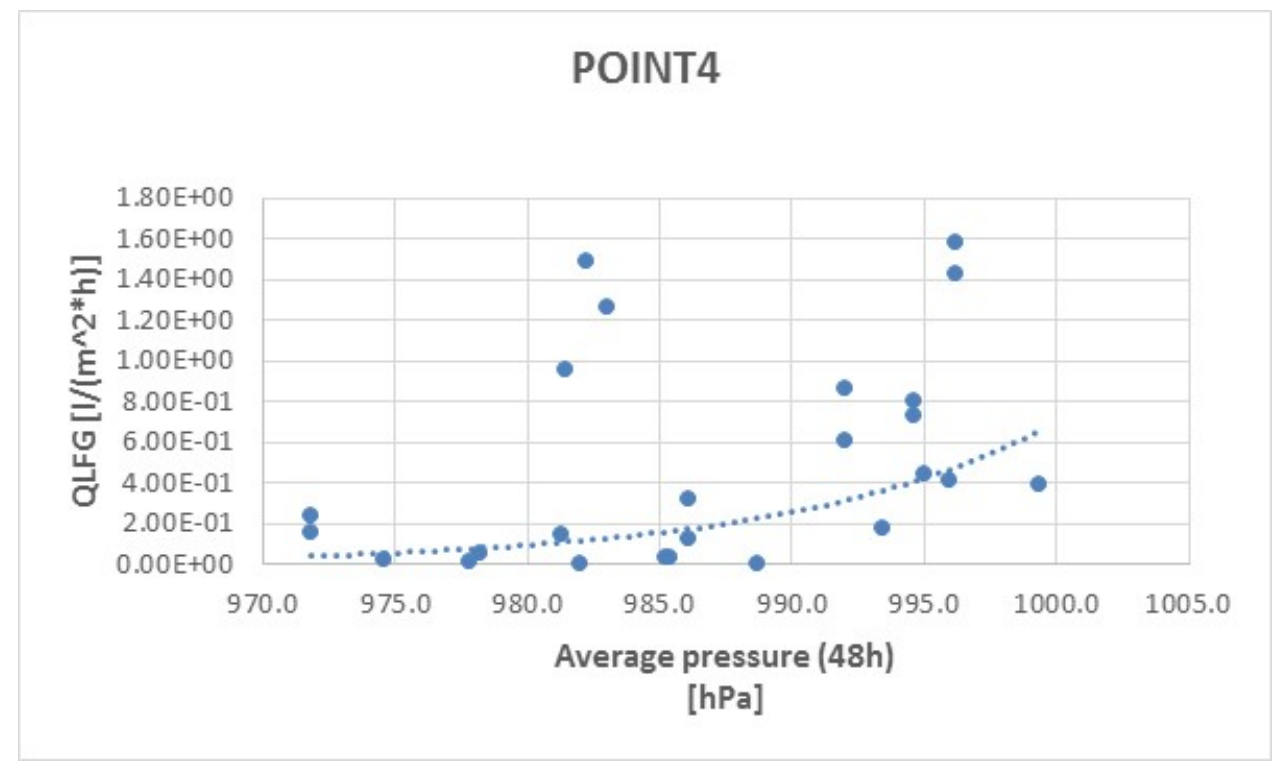

Figure 5. LFG emissions vs. average atmospheric pressure in the 48 preceding the sampling 


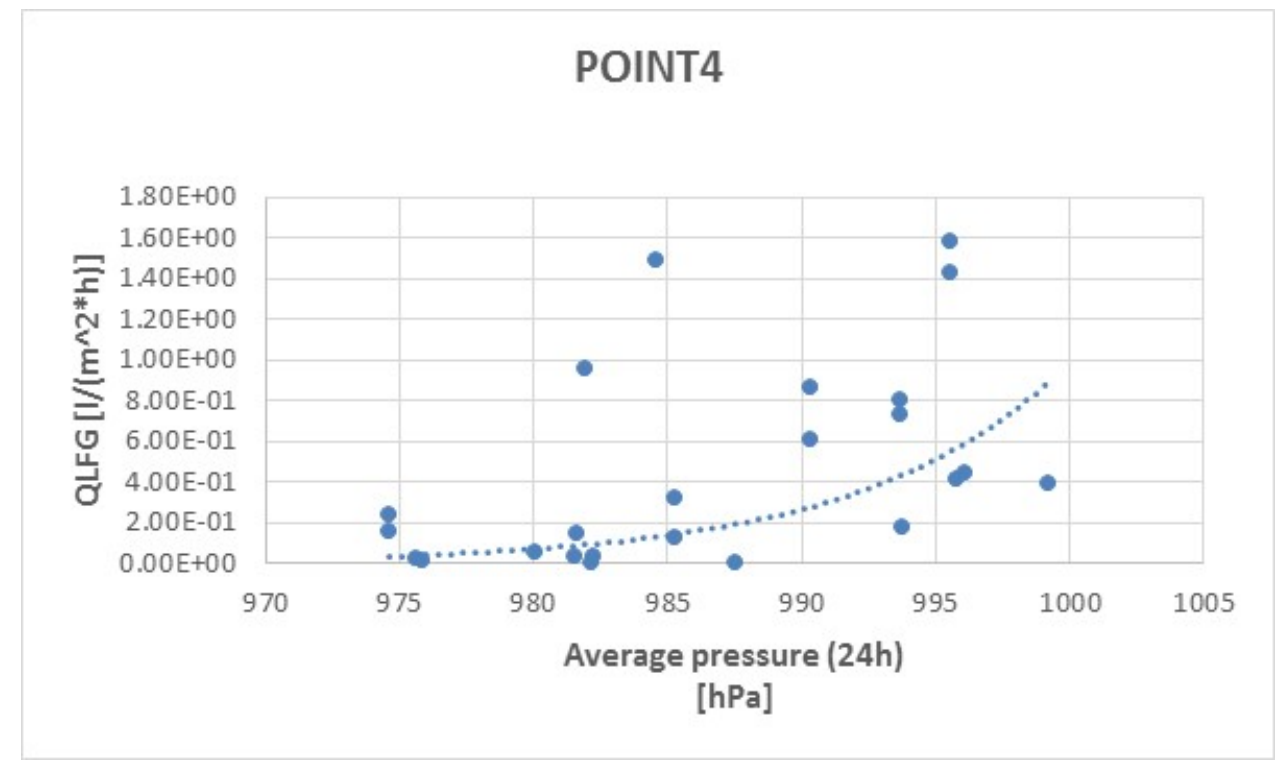

Figure 6. LFG emissions vs. average atmospheric pressure in the $24 \mathrm{~h}$ preceding the sampling

In order to verify the significance of the found correlations, they have been weighed by means of Spearman's correlation index. This index is evaluated from the ranks of the data series considered and it might assume values ranging from - 1 "perfect negative correlation" to +1 "perfect positive correlation", while a value of 0 indicates "no correlation" and the two data sets are unrelated. For the present situation, it is possible to obtain an index of 0.5 for the case of $48 \mathrm{~h}$ averaged pressure and 0.3 for the $24 \mathrm{~h}$ averaged pressure. Therefore, this seems to confirm that in both cases there is a moderate positive correlation between the LFG emissions and the pressure averaged over the hours preceding the measure; it also points out that the $48 \mathrm{~h}$ average pressure is a better comparison term than the $24 \mathrm{~h}$ one. It is necessary to underline that these values for the Spearman's index are very significant since they support the idea of a positive correlation, even if they are not very high (i.e. $>0.6$, that indicates strong to very strong correlation) fact that can also be a consequence of the experimental error. To clarify, obtaining indexes representative of a perfect correlation (or non-correlation) - i.e. $-1,0,+1-$ would be suspicious at best.

The same statistical investigation was carried out comparing LFG emissions and soil humidity. Fig. 7 shows the LFG fluxes plotted against the soil humidity referred to sampling point \#4. 


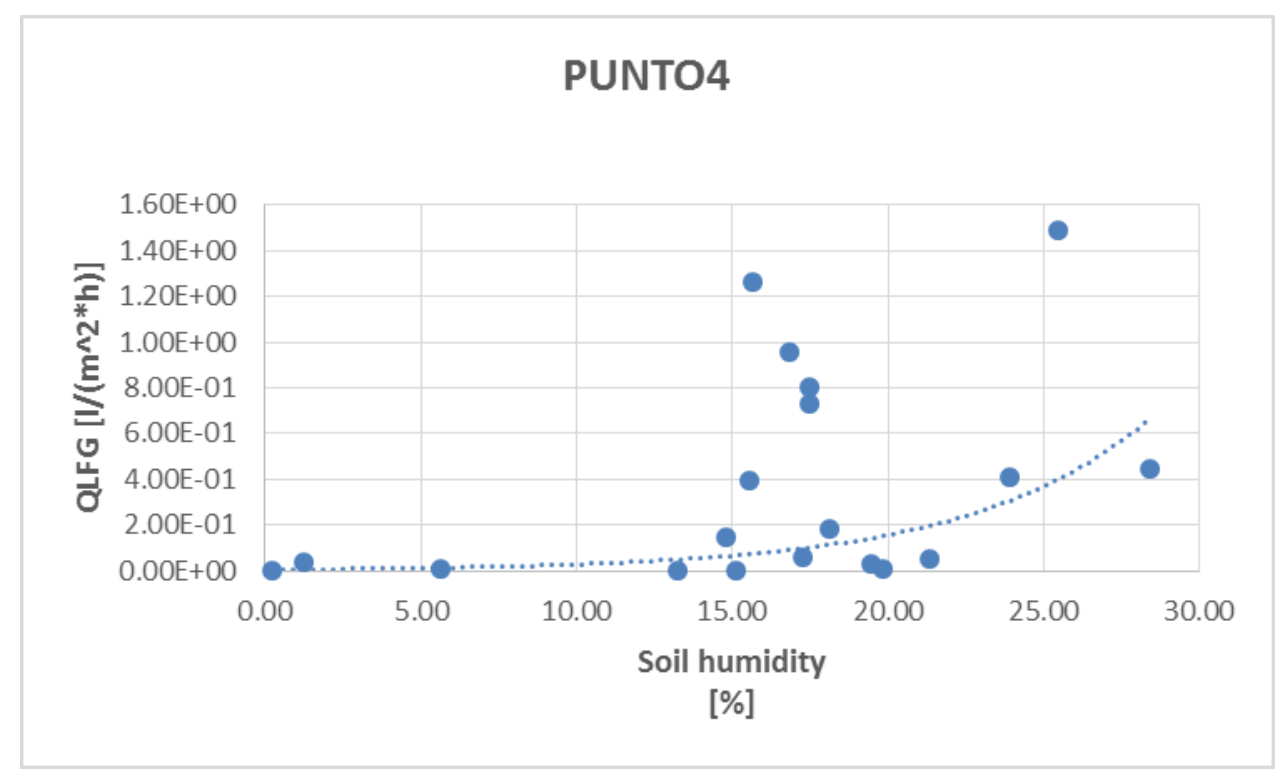

Figure 7. LFG emissions vs. soil humidity.

In this case the Spearman's index resulted equal to 0.7 , showing a strong positive correlation and confirming the hypothesized interrelationship: there is a significant positive correlation between the LFG emissions and the soil humidity, i.e. as soil humidity increases emissions increase accordingly. It is important to underline that this is true for days without significant rainfalls, since in such situations the socalled "cork effect" was observed, since a high amount of water blocks the LFG passage and emissions are typically zero. The explanation supposed for this finding is that - in a closed allotment - the produced leachate, because of gravity, trickles through the landfill body reaching the lower levels that therefore remain rather wet. On the contrary, the superficial levels tend to be dryer, in absence of leachate recirculation. Dryer environments are unfavourable for the waste biodegradation, thus the kinetics of the process become slower. In the days following a rainfall, water infiltrates the surface and wets the dry levels, resulting in a boost in the fermentation kinetics, thus augmented LFG emissions. Even though this observation does not lead directly to the formulation of a soil-humidity-dependent OEF, it might be of great importance for the landfill management.

From the evidences emerged both from the literature research and from the experimental work, it is possible to conclude that correlations may be identified between the LFG emissions from landfill surfaces and some environmental variables such as atmospheric pressure and soil humidity. 
However, the observations made up to now did not turn out to be sufficient in order to develop a "refined" OEF expressed as a function of specific meteorological variables. Nonetheless, these observations represent a useful basis for future research in this field. This might include the possibility to develop some sort of "macro-functions" for the definition for instance of seasonal OEFs, or as previously mentioned, to consider the linear combinations of different meteorological parameters.

\section{CONCLUSIONS}

The present study proposes an up-to-date methodology for the development of an Odour Emission Factor (OEF) for the estimation of odour emissions from landfills, thereby focusing on the odour emissions related to the emissions of landfill gas (LFG) from the landfill surface, which, due to its large extension compared to the other sections of the plant (e.g., fresh waste tipping, torches), as well as to the offensive odour character of LFG is recognized to be the main source of malodours from landfills.

An approach for the evaluation of the odour emissions and the odour impact relying on the direct measure of the odour concentration at the source - for the peculiar case of low emissivity sources - entails an intrinsic overestimation of the real emissions and the real impact, due to the risk of measuring odour concentration values that do not represent exclusively the characteristic odour of the LFG emitted through the landfill surface, but which include the so-called background odour relevant to the landfill surface itself and of its components (e.g. soil, grass).

For this reason, an indirect approach based on the measurement of the methane concentration over the landfill surface was preferred for the present research study for the estimation of the landfill Odour Emission Rate (OER). The (OER) in this case is obtained by multiplying the experimentally obtained emitted LFG flow rate by the LFG odour concentration. The odour concentration of the LFG emitted through the landfill surface was estimated by means of an ad hoc correlation investigated between methane concentration and odour concentration. 
The OEF for the estimation of odour emissions from landfill surfaces was therefore computed, considering the landfill surface as the activity index, as the product between the mean specific LFG flux emitted through the surface resulting from the experimental campaigns, equal to $0.39 \mathrm{l} / \mathrm{m}^{2} / \mathrm{h}$, and its odour concentration, which was estimated to be equal to $105^{\prime} 000 \mathrm{ou}_{E} / \mathrm{m}$, thus giving an $\mathrm{OEF}$ of $0.0113 \mathrm{ou} / \mathrm{m}^{2} / \mathrm{s}$. This value which is considerably lower than those published in previously published works, which are likely to have overestimated landfill odour emissions, mainly because of an obsolete sampling method. This new value should therefore be considered as an improved estimation, as it based on the most recent developments of the research in the field of odour sampling on surface sources.

This study also aimed to try determining a specific OEF for landfill surfaces, capable also to account for variations over time. There are some studies asserting that some meteorological parameters are correlated to LFG emissions from landfill surfaces, even though they mostly provide purely qualitative indications. This is the reason why, in this project, in order to define an OEF specific for the site studied capable of accounting for these variations, the possibility of defining quantitative correlations between specific emitted LFG flow and several atmospheric parameters was investigated.

From the evidences emerged both from an extensive literature research and from the experimental work, it is possible to conclude that correlations may be identified between the LFG emissions from landfill surfaces and some environmental variables such as atmospheric pressure and soil humidity, thereby not considering instantaneous values, but averaged ones in a previous time period, which are more representative of the landfill emissions.

However, the observations made up to now did not turn out to be sufficient in order to develop a "refined" OEF expressed as a function of specific meteorological variables. Nonetheless, these observations represent a useful basis for future research in this field. This might include the possibility to develop some sort of "macro-functions" for the definition for instance of seasonal OEFs, or as previously mentioned, to consider the linear combinations of different meteorological parameters. 


\section{REFERENCES}

Aatamila M., Verkasalo P.K., Korhonen M.J., Suominen A.L., Hirvonen M.R., Viluksela N.K., Nevalainen A., 2011. Odour annoyance and physical symptoms among residents living near waste treatment centres. Environmental Research 111, 164-170. DOI 10.1016/j.envres.2010.11.008.

Alexander A., Burklin C., Singleton A., 2005. Landfill Gas Emissions Model (LandGEM) Version 3.02 User's Guide, US EPA-600/R-05/047.

Capanema M.A., Cabana H., Cabral A.R., 2014. Reduction of odours in pilot-scale landfill biocovers. Waste Management 34, 770-779. DOI 10.1016/j.wasman.2014.07.008.

Capelli L., Sironi S., Del Rosso R., Céntola P., 2009a. Predicting odour emissions from wastewater treatment plants by means of odour emission factors. Water Research 43, 1977-1985. DOI 10.3303/CET1440033.

Capelli L., Sironi S., Del Rosso R., Centola P., 2009b. Design and validation of a Wind Tunnel system for odour sampling on liquid area sources. Water Science and Technology 59, 1611-1620. DOI 10.2166/wst.2009.123.

Capelli L., Sironi S., Del Rosso R., Guillot J.-M., 2013a. Measuring odours in the environment vs. dispersion modelling: A review. Atmospheric Environment 79, 731-743. DOI 10.1016/j.atmosenv.2013.07.029.

Capelli L., Sironi S., Del Rosso R., 2013b. Odor sampling: techniques and strategies for the estimation of odor emission rates from different source types. Sensors 13, 938-955. DOI 10.3390/s130100938.

Capelli L., Sironi S., Del Rosso R., 2014a. Odour Emission Factors: fundamental tools for air quality management. Chemical Engineering Transactions 40, 193-198. DOI 10.3303/CET1440033.

Capelli L., Sironi S., Del Rosso R., Magnano E., 2014b. Evaluation of landfill surface emissions. Chemical Engineering Transactions 40, 187-192. DOI 10.3303/CET1440032. 
Capelli L., Lucernoni F., Sironi S., 2015. Odour impact assessment by dispersion modelling: a comparison of different approaches for the estimation of odour emissions from landfill surfaces. Proceedings of Sardinia Symposium 2015, Santa Margherita di Pula (ITA), 5-9 October 2015. Organized by the International Waste Working Group (IWWG), c/o Hamburg University of Technology, Harburger Schlossstr. 36, 20179 Hamburg, Germany.

CEN, 2003. EN 13725:2003. Air quality - Determination of odour concentration by dynamic olfactometry, Brussels.

Chemel C., Riesenmey C., Batton-Hubert M., Vaillant H., 2012. Odour-impact assessment around a landfill site from weather-type classification, complaint inventory and numerical simulation. Journal of Environmental Management 93, 85-94. DOI 10.1016/j.jenvman.2011.08.016.

D.G.R. 15 febbraio 2012 - n. IX/3018 Regione Lombardia, 2012. Determinazioni generali in merito alla caratterizzazione delle emissioni gassose in atmosfera derivanti da attività a forte impatto odorigeno, 2049. Bollettino Ufficiale 20 febbraio 2012, Milano, Italy.

Dincer F., Odabasi M., Muezzinoglu A., 2006. Chemical characterization of odorous gases at a landfill site by gas chromatography-mass spectrometry. Journal of Chromatography A 1122, 222-229. DOI 10.1016/j.chroma.2006.04.075.

Hoff S.J., Bundy D.S., Nelson M.A., Zelle B.C., Jacobson L.D., Heber A.J., Ni J., Zhang Y., Koziel J.A., Beasley D.B., 2006. Emissions of ammonia, hydrogen sulphide, and odor before, during, and after slurry removal from a deep-pit swine finisher. Journal of the Air and Waste Management Association 56, 581-590.

Hudson N., Ayoko G.A., 2008. Odour Sampling. 2. Comparison of physical and aerodynamic characteristics of sampling devices: A review. Bioresource Technology 99, 3993-4007. DOI 10.1016/j.biortech.2007.03.043. Hurst C., Longhurst P., Pollard S., Smith R., Jefferson B., Gronow J., 2005. Assessment of municipal waste compost as a daily cover material for odour control at landfill sites. Environmental Pollution 135, 171-177. DOI 10.1016/j.envpol.2004.09.004. 
Klenbusch M.R., 1986. Measurement of gaseous emission rates from land surfaces using an emission isolation flux chamber. Radian Corporation, US EPA.

McBain M., Warland J., McBride R., Wagner-Riddle C., 2005. Micrometeorological measurements of N2O and $\mathrm{CH} 4$ emissions from a municipal solid waste landfill. Waste Management and Research 23, 409-419. DOI 10.1177/0734242X05057253.

McGinley C.M., McGinley M.A., 1998. Odor quantification methods and practices at MSW landfills. Proceedings of Air and Waste Management Association 91st Annual Meeting and Exhibition, San Diego (CA), 14-18 June 1998. Organized by the Air \& Waste Management Association, One Gateway Centre, 3rd Floor, 420 Fort Duquesne Blvd., Pittsburgh, PA 15222-1435, USA.

Nicell J.A., 2009. Assessment and regulation of odour impacts. Atmospheric Environment 43, 196-206. DOI 10.1016/j.atmosenv.2008.09.033.

Nicholas P., McGahan E., Watts P., 2002. Application of emission data in modelling and assessment. FSA Environmental, Australian Pork Ltd, Toowoomba, Queensland.

Park Jin-Won, Shin Ho-Chul, 2001. Surface emissions of landfill gas from solid waste landfill. Atmospheric Environment 35, 3445-3451. DOI 10.1016/S1352-2310(01)00118-2.

Rachor I.M., Gebert J., Grongroft A., Pfeiffer E.-M., 2013. Variability of methane emissions from an old landfill over different time-scales. European Journal of Soil Science 64, 16-26. DOI 10.1111/ejss.12004.

Reinhart D. R., Cooper D. C., Walker B. L., 1992. Flux chamber design and operation for the measurement of municipal solid waste landfill gas emission rates. Air and Waste Management Association 42, 1067-1070. DOI 10.1080/10473289.1992.10467053.

Romain A.C., Delva J., Nicolas J., 2008. Complementary approaches to measure environmental odours emitted by landfill areas. Sensors and Actuators B 131, 18-23. DOI 10.1016/j.snb.2007.12.005. 
Sadasivan B.Y., Reddy K.R., 2014. Landfill methane oxidation and bio-based cover systems: a review. Reviews in Environmental Science and Bio/Technology 13, 79-107. DOI 10.1007/s11157-013-9325-z.

Saral A., Demir S., Yildiz Ş, 2009. Assessment of odorous VOCs released from a main MSW landfill site in Istanbul-Turkey via a modelling approach. Journal of Hazardous Materials 168, 338-345. DOI 10.1016/j.jhazmat.2009.02.043.

Sarkar, U., Hobbs, S. E., 2002. Odour from municipal solid waste (MSW) landfills: A study on the analysis of perception. Environment International 27, 655-662. DOI 10.1016/S0160-4120(01)00125-8.

Sarkar U., Hobbs S.E., 2003. Landfill odor: assessment of emissions by the flux footprint method. Environmental Modelling \& Software 18, 155-163. DOI 10.1016/S1364-8152(02)00071-3.

Schauberger G., Piringer M., Petz E., 1999. Diurnal and annual variation of odour emission from animal houses: a model calculation for fattening pigs. Atmospheric Environment 74, 251-259. DOI 10.1006/jaer.1999.0457.

Schauberger G., Schmitzer R., Kamp M., Sowa A., Koch R., Eckhof W., Eichler F., Kypke J., Hartung E., 2012. Empirical model derived from dispersion calculations to determine separation distances between livestock buildings and residential areas to avoid odour nuisances. Atmospheric Environment 46, 508-515. DOI 10.1016/j.atmosenv.2011.12.010.

Schauberger G., Lim T.T., Ni J.Q., Bundy D.S., Haymore B.L., Diehl C.A., Duggirala R.K., Heber A.J., 2013. Empirical model of odor emission from deep-pit swine finishing barns to derive a standardized odor emission factor. Atmospheric Environment 66, 84-90. DOI 10.1016/j.atmosenv.2012.05.046.

Schauberger G., Piringer M., Heber A.J., 2014. Odour emission scenarios for fattening pigs as input for dispersion models: A step from an annual mean value to time series. Agriculture, Ecosystems and Environment 193, 108-116. DOI 10.1016/j.agee.2014.04.030. 
Sironi S., Capelli L., Céntola P., Del Rosso R., II Grande M., 2005. Odour Emission Factors for the assessment and prediction of Italian MSW landfills odour impact. Atmospheric Environment 39, 5387-5394. DOI 10.1016/j.atmosenv.2005.05.023.

Sironi S., Capelli L., Céntola P., Del Rosso R., II Grande M., 2006. Odour emission factors for the prediction of odour emissions from plants for the mechanical and biological treatment of MSW. Atmospheric Environment 40, 7632-7643. DOI 10.1016/j.atmosenv.2006.06.052.

Sironi S., Capelli L., Céntola P., Del Rosso R., II Grande M., 2007. Odour emission factors for assessment and prediction of Italian rendering plants odour impact. Chemical Engineering Journal 131, 225-231. DOI 10.1016/j.cej.2006.11.015.

Sironi S., Capelli L., Dentoni L., Del Rosso R., 2013. Odour Regulation and Policies, in: Belgiorno V. et al. (Eds.), Odour Impact Assessment Handbook, Wiley, Chichester, pp. 175-186.

Solan P.J., Dodd V.A., Curran T.P., 2010. Evaluation of the odour reduction potential of alternative cover materials at a commercial landfill. Bioresource Technology 101, 1115-1119. DOI 10.1016/j.biortech.2009.09.030.

Sucker K., Both R., Winneke G., 2009. Review of adverse effects of odours in field studies. Water Science and Technology 59, 1281-1289. DOI 10.2166/wst.2009.113.

United Kingdom Department for Environment, Food and Rural Affairs (UK Defra), 2010. Odour guidance for local authorities, London, UK.

United Kingdom Environment Agency (UK EA), 2010. Guidance on monitoring landfill gas surface emissions, Bristol, UK.

United States Environmental Protection Agency (US EPA), 1995. Compilation of Air Pollutant Emission Factors, AP-42, Fifth Edition, Volume I: Stationary Point and Area Sources. Research Triangle Park, NC, USA. 
